\title{
O ensino da leitura no livro didático: uma avaliação, uma expectativa
}

\author{
TEACHING OF READING IN THE TEXTBOOK: AN EXAMINATION, A \\ PROSPECT
}

Aparecida Feola SELLA *

\begin{abstract}
Resumo: Apresenta-se pesquisa acerca do ensino da leitura em livro didático direcionado para a $5^{\text {a }}$ série (atual sexto ano), com enfoque na forma como foi direcionada a formação de um leitor inquiridor. Objetiva-se demonstrar os vínculos possíveis entre as unidades do livro, estabelecidos para a leitura investigativa, das entrelinhas, e, portanto, do implícito. Considera-se a leitura numa perspectiva mais ampla e ainda a importância da modalidade oral. Faz-se uma pequena discussão relativa ao trabalho com a leitura na escola e tenta-se esboçar a análise realizada sobre o livro didático. Apresentam-se comentários acerca dos resultados obtidos, e ainda apresentam-se considerações relativas a possibilidades de se trabalhar de forma diferenciada as unidades do livro didático sob análise.
\end{abstract}

Palavras-chave: Livro didático; Leitura; Implícito.

\begin{abstract}
This article presents research on the teaching of reading in a textbook for the 5 th grade, focusing on the way of leading the education of an inquisitive reader. The aim is to present the possible links between the units of the book, established for an investigative reading, that is, a reading between the lines and, consequently, a reading of the implicit meanings. In this study, reading is viewed in a broader perspective, and the importance of oral language is considered as well. Firstly, a brief discussion on the reading approach in the school is presented, and then a preliminary analysis on the textbook is carried out. Finally, the text presents some comments on the results, as well as some considerations about the possibilities of approaching the units of the book in a different way.
\end{abstract}

Key-words: Textbook; Reading; The implicit.

* Doutora em Letras pela UNESP-Assis. Professora da Unioeste, Cascavel. Contato: afsella1@yahoo.com.br. 


\section{Introdução}

Leitura é interação. Essa seria, talvez, uma forma breve de descrever orientações que geralmente aparecem nos livros didáticos de língua portuguesa do ensino fundamental. Em parte, trata-se de uma forma de responder às expectativas presentes em documentos oficiais, em planejamentos escolares, e mesmo nos anseios de cada professor. Esse quadro pode ser uma das explicações para o retorno ou mesmo permanência de questões acerca de quais estratégias de leitura podem ser aplicadas ao ensino. Esse assunto é percebido nos vários veículos de disseminação na área da Linguística e lembra preocupações presentes nos trabalhos de Linguística Aplicada. Paes (1991) comenta que problemas estudados e reestudados em Linguística Aplicada, e a persistência com que algumas questões "voltam a ser estudadas" fazem com que se tornem "temas mais centrais". O autor, inclusive, apresenta um rol de perguntas, das quais destacamos "Como são feitas e mantidas as relações entre as pessoas através da linguagem?”

Para Paes (1991), há questões que colocam o pesquisador "face a face com a vasta gama de situações de uso de linguagem que podem, quando adversamente configuradas, tornar nossa vida mais difícil. Essas questões merecem, portanto, um tratamento sistemático, objetivo e explícito de parte do linguista aplicado". Nossa pesquisa segue, em parte, o rumo dessas preocupações. Depois de uma análise mais ampla, no interior da qual observamos o ensino da leitura e da análise linguística e suas correlações, hipóteses e recorrência a teóricos, apresentamos aqui uma proposta de trabalho com unidades de um livro didático de língua portuguesa voltado para a $5^{\mathrm{a}}$ série (sexto ano), as quais referendam o objetivo de formar um leitor inquiridor. Pretendemos demonstrar os vínculos possíveis entre as unidades do livro pesquisado, a partir do conteúdo mais geral, estabelecido para a leitura investigativa, das entrelinhas, e, portanto, do implícito.

Considera-se, pois, que o professor deve ir além da proposta explícita dada pelo livro e expandir os horizontes do conteúdo e da metodologia de trabalho propostos, e isso, digamos, também por meio de perspectivas que surgem a partir da própria temática e dos conceitos postos para o aprendizado do aluno. Para fins de apresentação da discussão, este artigo está composto por três partes. Na primeira, 
faz-se uma pequena discussão relativa ao trabalho com a leitura na escola. Na segunda parte, fica a tentativa de esboçar a análise realizada sobre o livro didático Trabalhando com a Linguagem, $5^{\text {a }}$ série (atual sexto ano), de Ferreira et al. (2004), utilizado no ano de 2009 por escolas da cidade de Cascavel, com o objetivo de apresentar uma breve discussão acerca de formas alternativas de lidar com o conteúdo de cada unidade do livro didático. $\mathrm{Na}$ terceira parte, são tecidos comentários acerca dos resultados obtidos, e ainda considerações relativas a possibilidades de trabalhar de forma diferenciada as unidades, as quais, mais uma vez explicitamos, seguem as perspectivas atuais com relação ao ensino da leitura.

\section{Formação de um aluno leitor: algumas preocupações}

Destacamos nesta parte alguns objetivos verificados no livro sob análise: 1. Leitura como uma forma ampla de ler o mundo; 2. Leitura não apenas centrada no texto escrito; e, por fim, 3. Estratégias de leitura investigativa, tendo o leitor um objetivo claro ao se deparar com qualquer tipo de texto.

Se tomados os autores consultados até o presente momento, percebemos que as preocupações acima estão relacionadas às múltiplas possibilidades de lidar com o texto, tendo em vista ora a autoria, ora o leitor, ora o texto em si, ora todos os fatores considerados no processo de interação que é a leitura. Numa visão panorâmica da situação, podese dizer que esse quadro segue o objetivo de formação do leitor investigativo, e é por isso que estamos sondando o trabalho com o implícito nos livros didáticos.

Ler o implícito é uma tarefa que requer a compreensão de categorias vinculadas a essa atividade. Embora o livro didático tenha em si um encaminhamento por meio de normas (veja Aparício, 2009), uma vez que rege as ações do professor, esse trajeto pode ser permeado de enfoques inter-relacionados, como se o trabalho não se esgotasse ao final de cada unidade do livro, mas acionasse o exercício da leitura de outros livros, de ruas, de pessoas, enfim, de mundo, o que pode garantir a leitura do implícito.

Além disso, deve-se considerar que todo ato de leitura requisita como ato antecedente um objetivo norteador. Para levar o aluno a ler, 
é preciso criar expectativas em meio a um desejo irresoluto de "saber". Ou seja: a leitura reclama objetivos claros e motivadores de tal sorte que o leitor centre sua atenção nos dados que são pertinentes aos seus propósitos. Essa preocupação já foi bastante discutida por vários autores (ver, por exemplo, Terzi, 1995, em especial no Capítulo 4, em que a autora discute a apropriação ou normatização do texto escrito).

Selecionamos para sondagem de pesquisa a parte do livro, sob análise, intitulada Leitura das Linhas e da Entrelinhas, dedicada ao ensino da leitura de "uma informação subentendida (implícita) no texto" (aqui usamos a expressão tal qual anunciada no livro, p. 16). Para fins de ilustração, tentamos demonstrar que, nesta unidade em particular, há um trabalho de interpretação que requisita conhecimentos acerca do que é implícito, do que é um leitor proficiente.

\section{$2 \mathrm{O}$ ato de ler: além do escrito}

Partamos do princípio de que o professor deva recorrer a conceitos propostos na área da Linguística para que possa elucidar formas alternativas de lidar com o ensino da leitura. Tomemos uma noção ampla de leitura. Orlandi (1988, p. 38) explica com bastante clareza que a relação

[...] do aluno com o universo simbólico não se dá apenas por uma via - a verbal -, ele opera com todas as formas de linguagem na sua relação com o mundo. Se considerarmos a linguagem não apenas como transmissão de informação, mas como mediadora (transformadora) entre o homem e sua realidade natural social, a leitura deve ser considerada no seu aspecto mais conseqüente, que não é o de mera codificação, mas o da compreensão.

A autora traça um rumo argumentativo bastante interessante, que gera a expectativa mais próxima de um ideal de ensino, pois eleva o valor de outras formas de linguagem, e não enfoca somente o texto escrito como o centro das preocupações da escola. Dessa forma, Orlandi provoca uma reflexão acerca do aluno-leitor que a escola constitui, e acerca da articulação que existe entre todas as formas de 
linguagem, e que nenhuma forma deve ser vista como alternativa (em segundo plano, digamos).

A nossa discussão, que se aproxima dessa observação de Orlandi, estabelece-se na compreensão de que o livro didático muitas vezes ensina saberes que estão vinculados a segmentos sociais e a estereótipos da língua escrita. Não se reconhecem, de forma devida, as variadas formas de repasse de informações. E as várias linguagens que circulam e se entrecruzam acabam sendo tangenciadas por conhecimentos atrelados a práticas que se localizam em esferas sociais um tanto distantes do cotidiano do aluno.

Essa situação rende uma pergunta em particular: O que se objetiva com o ensino da língua portuguesa? Se partirmos da noção de que o texto é uma unidade que deve ser ensinada, podem-se buscar comentários interessantes presentes em Orlandi (1988): "Todo texto em relação à leitura teria, pois, pontos de entrada e vários pontos de fuga. Os pontos de entrada correspondem a múltiplas posições do sujeito. Os pontos de fuga são diferentes perspectivas de atribuição de sentidos". Sendo assim, segundo a autora, os sentidos não caminham "em linha reta", o que significa dizer que a "relação entre o sujeitoleitor e o texto não é, pois, nem direta nem mecânica”. E certas correlações acabam sendo mais bem acionadas pelos alunos se a atenção também se volta ao enredo da língua oral.

Marcuschi (2005), ao comentar sobre a oralidade e o ensino de língua, explica que muitos autores de livros didáticos concebem que a língua falada seja captada somente na imanência do código, ou seja, trata-se apenas de uma questão lexical. Esse particular cuidado com as possíveis interpretações, mediante expectativas residentes na heterogeneidade de qualquer contexto produzido em sala, revela que se deva criar um espaço de interlocução para que o aluno possa vislumbrar seu particular interesse pela temática e por seu próprio texto (ou seja, estar motivado a se posicionar e a cuidar da forma como vai externar isso no interior do seu texto). Sendo assim, a preocupação com a leitura do implícito deve esbarrar no cuidado com o texto oral ou mesmo oral-dialogado, pois se trata de uma forma de construção de informações, de cultura, de crenças, de argumentos. $\mathrm{O}$ aluno deve estar atento a esta modalidade e deve dela saber tirar proveito para o processo de leitura 
Dessa forma, fixa-se a importância de assimilar a funcionalidade dos textos, os quais, de acordo com Koch (2001), são formas de cognição social, excelentes meios de intercomunicação, o que revela, portanto, questões a serem consideradas pelos professores quando forem lidar com os livros didáticos. Neste sentido, certas informações são retratos de ações socialmente localizadas, que podem ser medidas e avaliadas se forem trazidas para o interior da escola cenas do cotidiano, o que pode se dar por meio de narrativas, por meio de depoimentos. Por outro lado, Marcuschi (2005), ao discutir o problema da compreensão no contexto dos livros didáticos de português, observa que nem todos os livros são claros quanto à seção em que exercitam a compreensão. Pelo entendimento do autor, os exercícios de compreensão não são estabelecidos por meio de critérios e não se explicita o que seja "compreensão".

É possível perceber que os livros didáticos selecionam roteiros teóricos que orientam conceitos e também o material (discursivo, pictórico, algébrico, etc) mais adequado para fins de explicação. O que se disse até agora corrobora várias conclusões já emitidas por muitos linguistas, mas a principal, em nosso modo de conceber a situação, reside na busca de condições que promovam a leitura em uma interação de fato.

\section{Unidade de livro didático: à espera da atuação do professor}

$\mathrm{Na}$ seção Leitura das Linhas e das Entrelinhas, doravante referenciada pela sigla LLE, percebe-se uma espécie de exposição progressiva de conceitos que devem ser ensinados aos alunos como se fossem estratégias de leitura. O subtítulo de cada subparte é esclarecedor nesse sentido: Unidade 1 - Noção de leitura / Importância da leitura; Unidade 2 - Informações visuais e hipóteses; Unidade 3 - Nas teias da publicidade / Público alvo; Unidade 4 - Objetivos de leitura / Modos de leitura; Unidade 5 - Silhueta de um texto; Unidade 6 Leitor crítico; Unidade 7 - Estratégias de leitura: uma prática consciente; Unidade 8 - Leitura Seletiva. Daremos, contudo, enfoque somente às Unidades 4, 6, e 8, pois o nosso objetivo é demonstrar vínculos que essas unidades suscitam. 
Logo na primeira unidade, a LLE comporta duas partes, conforme rapidamente demonstrado acima. Na parte Noção de Leitura, aparece a preocupação com a leitura das entrelinhas, o que fica vinculado a "informações adquiridas por meio de experiências anteriores" (veja p. 16). Para lidar com essa noção, é apresentada uma tira de O Menino Maluquinho. Transcrevemos o diálogo sequencialmente posto: Bocão: Ei! Eu tenho um plano astuto pra gente não virar adolescente. Bocão: Adolescentes são aqueles caras da quinta à oitava série, nê? Menino Maluquinho: Correto! Bocão: Basta a gente não passar mais de ano.

O exercício relativo a essa tira é o seguinte: a) Segundo um dos personagens, quem são os adolescentes? A partir da leitura do texto, em qual série o Menino Maluquinho pode estar? b) Explique como chegou à resposta. Depois da explicação dos autores, apresenta-se o seguinte enunciado: "Na questão $\mathbf{b}$, você precisou refletir para chegar a uma conclusão, isto é, teve de identificar uma informação subentendida (implícita) no texto: você fez a leitura das entrelinhas". (veja p. 68 e 69).

A ideia de implícito orientada acima esbarra em conceitos um tanto complexos. Tomemos o conceito de pressuposição, inicialmente. Trata-se de um fenômeno ligado ao teor próprio dos elementos linguísticos presentes nos enunciados, deduzido da orientação de sentido vinculada ao linguístico propriamente dito, segundo a visão de Ducrot (1987). O pressuposto é, portanto, parte integrante do sentido do enunciado. Quando se produz um enunciado do tipo 1. O professor terminou de corrigir as provas, está se dizendo também que 1.1 O professor estava corrigindo as provas anteriormente. Em 1.1, tem-se uma informação apresentada à margem do discurso, verificada na locução verbal terminou de corrigir.

Por outro lado, pode-se pensar numa categoria como o subentendido, dispositivo que acena para o cuidado com o próprio processo em si. Ducrot (1987) explica da seguinte forma: em Pedro parou de fumar, há, na instância do dito, uma afirmação do tipo Ele não fuma mais, e, na instância do pressuposto, Ele fumava antigamente. Num processo interlocutivo, se poderia dizer que o enunciado suscita interpretações como Parar de fumar éprova de força de vontade, subentendido que pode servir de pressuposto para Você precisa ter força de vontade e parar de fumar. 
Portanto, é preciso recorrer ao sentido das palavras ou sentenças de uma língua, uma vez que os seus componentes podem ser tomados de forma particular a cada atualização dos enunciados. Sendo assim, a informação também relativa ao fato de que antes se estava desenvolvendo certa atividade, como em O professor terminou de corrigir as provas, pode render processos interpretativos importantes para a leitura mais global do texto.

$\mathrm{O}$ enunciado $O$ professor terminou de corrigir as provas rende-se à intencionalidade do locutor e às circunstâncias de sua produção. Os sentidos podem estar atrelados a uma orientação geral, do tipo "Ela conseguiu”, “Enfim ela terminou”, "Ela pode passear”. São interpretações possíveis e captadas por meio do próprio enunciado (para recorrer à proposta de Ducrot (1987) com relação ao subentendido). $\mathrm{O}$ interlocutor passa a avaliar o enunciado de acordo com seu conhecimento prévio sobre o assunto.

Seguindo-se ilustrações de Geraldi e Ilari (1986), a inferência é um ato mais centrado na própria situação de enunciação. $\mathrm{O}$ interlocutor avalia as condições de realização do enunciado para poder avaliar o sentido ou os sentidos que são mais globalmente construídos. São respostas a perguntas do tipo Por que ele/ela falou assim? Neste caso, o receptor da mensagem realiza um trajeto de análise que seria parecido com o seguinte: O professor terminou de corrigir as provas. Se isto foi dito para mim, deve ser porque en preciso preparar o livro de chamada? Percebe-se que este último sentido está mais atrelado às condições de realização do enunciado e envolve os vários agentes do processo interativo.

Com esses breves comentários, fica registrada a nossa intenção de demonstrar categorias que podem ser auxiliares para o trabalho com a leitura do implícito. Indicamos o livro Para entender o texto: leitura e redação, de Platão e Fiorin (1999), em que os autores apresentam estratégias de como lidar com informações implícitas (direcionamos um olhar mais detido para as Lições 22 e 27).

Com relação aos vínculos entre cada unidade do livro sob estudo, percebemos que as Unidades 4, 6, e 8 tratam de conteúdo que poderia ser administrado sequencialmente, ou seja, as informações repassadas acerca da leitura das entrelinhas, tal como administradas nessas unidades, poderiam ser concebidas como uma progressão do conteúdo. Nesse sentido fica mais uma vez a sugestão de avaliar o livro a partir de uma 
leitura pautada nas inter-relações possíveis que o próprio livro oportuniza sem que isso seja uma orientação evidente ou direcionada pelos autores.

Sendo assim, passamos a falar dessas LLEs, tratando-as de forma interligada até mesmo para mostrar ao professor formas alternativas de aproveitar o que os livros didáticos nos oferecem. Então, passemos para a da Unidade 4, a mais importante, em nosso ponto de vista, em termos de conceituação acerca da leitura das entrelinhas. Inicialmente, apresentam-se os "objetivos da leitura", os quais são relacionados pelos autores ao fato de que os "procedimentos de leitura dependem das intenções e necessidades do leitor” (p. 68).

Alguns objetivos de leitura são apresentados e explicados. São eles: Leitura do ambiente; Leitura para informação; Leitura para lazer; Leitura para estudo do texto; Leitura pretexto. As explicações sugerem um trabalho até interdisciplinar, por meio da seguinte diretiva: o "mesmo texto pode ser lido em momentos diferentes com objetivos variados. A leitura de um mapa, por exemplo, pode ser feita para estudo do texto (Geografia, História), para se informar (localização), por simples curiosidade (conhecer novos lugares)" (veja p. 69 do livro). Registre-se ainda que os autores acenam para a importância do modo como deve ser desenvolvida a leitura. Citam alguns modos e os explicam: Leitura Global. Leitura tópica, Leitura item a item. Finalizam a explanação com as seguintes observações: "Como você pôde perceber, são as características de um texto e os objetivos do leitor que vão orientar o modo ou os modos como esse texto pode ou deve ser lido. Às vezes, o leitor emprega mais de um modo de leitura, conforme as necessidades de interação com um determinado texto" (p. 69).

Para demonstrar que cada texto exige modos de leitura diferentes, selecionam-se três tipos de texto: um com fins instrucionais, pois se trata da explicação do como lidar com o as regras do jogo da memória, outro é uma charada (do folclore brasileiro) e o último é o recorte de uma lista telefônica, o que, do nosso ponto de vista, cumpre o papel presente nos objetivos de formar um leitor atento aos vários tipos de texto (para não dizer gêneros).

$\mathrm{Na}$ Unidade 6 - tem-se como pauta de trabalho Procedimentos de um leitor crítico. A preocupação com a leitura das entrelinhas se sustenta agora por meio de procedimentos julgados relevantes para que se 
constitua um leitor crítico. São eles: "faz perguntas procurando pistas que o levem à compreensão; completa as informações dadas com o conhecimento que tem; cria hipóteses e antecipa acontecimentos; reconstrói para si o texto lido, fazendo críticas e reflexões sobre o conteúdo, descobre as possíveis intenções do autor; reconhece um texto presente em outro. Esses tópicos são rapidamente explicados e o último explicado por meio de processos de intertextualidade criados com um texto e o texto-base da Unidade (veja páginas 107 e 108). Na Unidade 8, a LLE tem como mote a Leitura Seletiva, e a atenção se volta para questões como "gosto pessoal, a necessidade, os objetivos de leitura de cada leitor” (p. 140, 141).

Enfim, as LLEs avaliadas retratam a importância da leitura, para o que é explorada uma gama variada de textos que circulam no cotidiano. Percebemos que as autoras esperam que os alunos concebam a leitura como uma das formas de interação nos meios sociais, inclusive como lazer. O conteúdo das Unidades pode servir para resgatar mais diretamente algumas categorias de leitura, inclusive as direcionadas para o texto jornalístico, o que reforça a posição de Bezerra (2005, p. 45): os "textos jornalísticos estão cada vez mais presentes nas aulas e manuais de língua, não só no Brasil, mas também em outros países (o que demonstra a influência da mídia no mundo em geral e uma prática de letramento presente e difundida entre vários povos). A autora ainda observa a tendência de uso de tiras, história em quadrinhos e propagandas, retiradas de jornais e revistas, para leitura e estudos gramaticais. Isso se comprova não somente nas LLEs analisadas, mas também no livro como um todo.

\section{Algumas considerações}

Diante de um olhar mais diretamente ligado às seções voltadas para o ensino da leitura, pode-se expressar certa satisfação diante do cuidado, verificado no livro, com a formação do leitor. Em se tratando de aplicação ao ensino, o livro didático sob análise torna-se alvo de reflexões, muito bem vindas sob nosso ponto de vista, porque carrega aquela indagação: como formar um leitor proficiente. A constituição desse leitor ideal requer dos autores a sondagem de quais estratégias podem ser aplicadas em sala de aula, as quais geralmente se voltam para o mundo da escrita. 
Esperamos que, diante da análise apresentada, fique a impressão de que o livro Trabalhando com a Linguagem, nas partes intituladas Leitura das Linhas e Entrelinhas (LLE), investe no ensino da leitura no ensino fundamental, uma vez que se promovem estratégias para obter tal intento, embora entendamos ser pertinente uma reordenação dos conteúdos, o que, de certa forma, o próprio professor poderia promover se acionasse uma leitura em que as LLEs fossem interligadas. O êxito dos autores paira no que Silva (1988, p.20) já vem dizendo há algum tempo: "uma concepção de leitura não pode deixar de incluir movimentos da consciência, voltados ao questionamento, à conscientização e à libertação."

As LLEs também revelam o que para Marcuschi (2008, p. 229230) é necessário de ser entendido: a compreensão não é uma tarefa individual, isolada do meio da sociedade em que se vive. $\mathrm{O}$ autor apresenta em seu trabalho questões do tipo: 1) entender um texto não equivale a entender palavras ou frases; 2) entender as frases ou as palavras é vê-las em um contexto maior; 3) entender é produzir sentidos e não extrair conteúdos prontos; 4) entender o texto é inferir numa relação de vários conhecimentos. A isso em geral subjazem algumas suposições bastante centrais, como: 1) os textos são em geral lidos com motivações muito diversas; 2) diferentes indivíduos produzem sentidos diversos com o mesmo texto; 3) Um texto não tem uma compreensão ideal, definitiva e única; 4) Mesmo que variada, as compreensões de um texto devem ser compatíveis; 5) em condições socioculturais diversas, temos compreensões diversas do mesmo texto (MARCUSCHI, 2008, p. 233-234).

Ou seja, o que observamos nas unidades analisadas segue as preocupações dos pesquisadores que lidam com o processo de leitura e compreensão e também com o contexto escolar. Para Angelo e Menegassi (2008):

Ler, então, numa perspectiva interacionistadiscursiva, é o leitor relacionar-se mediante o texto com a memória discursiva. Nesse sentido, o leitor competente é aquele capaz de desencadear um processo de interação com o texto, levando em conta os aspectos cognitivos (diferentes objetivos, conhecimentos e estratégias) e os aspectos discursivos (os outros discursos que trazem 
significação ao texto). Esse conceito requer que se reconheça que: a) toda leitura envolve uma produção - e não uma extração, simplesmente - de sentidos, constituídos a partir do saber do leitor e das circunstâncias da leitura; b) tanto os ditos como os não-ditos fazem parte do texto; assim, saber ler significa perceber a incompletude do texto e desfazer os efeitos de transparência; e c) cabe ao leitor perceber as estratégias de manipulação presentes no texto, o que o torna um sujeito ativo, capaz de perceber a ideologia presente no texto, questioná-la, julgá-la e colocar-se contra.

É nesse sentido que tentamos demonstrar como é possível fazer uma reflexão acerca da forma como as unidades desses livros estão construídas e de como é possível vincular conteúdos entre elas. A nossa pesquisa se insere, portanto, de forma singela, no que Rangel (2005, p.19) anuncia como uma forma de oferecer instrumentos adequados aos desafios postos aos livros didáticos. $\mathrm{O}$ autor faz referência ao que chama de requisitos, dos quais destacamos a presença de "textos diversificados e heterogêneos, do ponto de vista do gênero e do tipo de texto, de tal forma que a coletânea seja o mais possível representativa no mundo da escrita", e a ciência de que é necessária a mobilização correta da "língua oral, quer para o desenvolvimento da capacidade de falar/ouvir, quer para e exploração das muitas interfaces entre oralidade e escrita". Segundo o autor, para "atender a esses requisitos, o LDP (Livro Didático de Português) precisará enfrentar novos objetos didáticos do ensino da língua materna: o discurso, os padrões de letramento, a língua oral, a textualidade, as diferentes gramáticas de uma mesma língua etc."

Rangel chega a mencionar "uma virada pragmática ainda não completada nem suficientemente amadurecida" e que a avaliação do livro didático é "um processo em andamento, de que participam não só a comissão oficial do MEC, na execução de determinado PNLD, mas também os educadores diretamente envolvidos com a questão, e até mesmo outras instâncias e agentes de letramento" (RANGEL, 2005, p. 19-21).

Não seria de outra forma, portanto, que se mostram nossos comentários neste artigo: na medida do possível, a intenção foi a de 
propor uma interlocução mais ativa do professor diante do livro didático, o que pode ser implementado por meio de sondagens teóricas, participação de cursos, e avaliação da aplicação dos próprios livros ao final de cada ano.

Para finalizar nossos comentários, reportamo-nos à fala de Terzi, tendo em vista que o exercício da leitura do implícito exige um olhar mais amplo, para todo o tipo de texto e na modalidade oral e escrita. Vejamos a fala da autora:

A concepção de leitura e produção de textos dos professores os leva a uma ênfase na decodificação de palavras como um fim em si mesma, que se concretiza na proposta de exercícios mecânicos sobre o texto, não envolvendo a busca do significado do mesmo. Isto faz com que as crianças criem uma pseudolinguagem, para falar do texto, que foge aos padrões de uso da linguagem por centrar-se na forma e não no sentido. Rompe-se, então, o processo de desenvolvimento tanto da expressão oral das crianças como da leitura, uma vez que não lhes é permitido estabelecer relações entre a linguagem oral e escrita. (TERZI, 1995, p. 148)

Não se enfatiza propriamente em nossa sondagem a importância da linguagem oral, mas o quanto o exercício da linguagem nessa modalidade pode ser útil para o processamento da leitura e principalmente da leitura do implícito, ou das entrelinhas, para usar uma expressão adotada no livro didático de que ora estamos falando. Tomando-se como ponto de partida o fato de que os textos escritos formam "um conjunto virtual de formas de expressão" que deles esperamos (veja Landsmann, 1995), e que os livros didáticos estão permeados de atividades que regem o objetivo de sondagem da leitura mais detidamente na escrita, podemos entender, portanto, o vasto conjunto de estratégias que são lançadas para 1. suscitar a utilidade do ato da leitura, 2. a consequente prática efetiva de tal ato e 3. a avaliação $\mathrm{da}(\mathrm{s})$ leitura(s) empreendida(s) por parte dos alunos. Esse caminho está posto de certa forma nos livros didáticos, mas se trata de questões que requerem um cuidado permanente e constante avaliação das estratégias propostas. 


\section{Referências}

ALMEIDA FILHO, J. C. P. Maneiras de compreender a linguística aplicada. Letras, Santa Maria, v. 2, 1991. Disponível em: <http:// w3.ufsm.br/revistaletras/artigos_r2/revista2_1.pdf $>$. Acesso em: 23 fev. 2010.

ANGELO, C. M. P.; MENEGASSI, R. J. Desempenhos em leitura nas séries finais de ciclo. Acta Scientiarum - Language and Culture, Maringá, v. 30, n. 2, p. 129-137, 2008.

APARÍCIO, A. S. M. A análise linguística no livro didático: contribuições para melhor compreensão do trabalho realizado em sala de aula por professores que estão buscando inovar sua prática de ensino de gramática. Estudos Linguísticos, São Paulo, v. 38, n. 2, p. 75-88, maio/ago. 2009.

DUCROT, O. O dizer e o dito. Campinas: Pontes, 1987.

FERREIRA, G.; CORDEIRO, I. C.; KASTER, M. A. A.; MARQUES, M. Trabalhando com a linguagem. São Paulo: Quinteto, 2004.

ILARI, R.; GERALDI, J. W. Semântica. 2. ed. São Paulo: Ática, 1985. KOCH, I. V. Argumentação e linguagem. São Paulo: Cortez, 2001.

LANDSMANN, L. T. Aprendizagem da linguagem escrita. São Paulo: Ática, 1995.

MARCUSCHI, A. Compreensão de texto: algumas reflexões. In: In: DIONÍSIO, A. P.; BEZERRA, M. A. O livro didático de português. 3. ed. Rio de Janeiro: Lucerna, 2005.

MARCUSCHI, A. Produção Textual, análise de gêneros e compreensão. São Paulo: Parábola, 2008.

ORLANDI, E. P. Discurso \& leitura. Campinas: Cortez; Editora da UNICAMP, 1988. 
PLATÃO SAVIOLI, P.; FIORIN, J. L. Para entender o texto: leitura e redação. São Paulo: Ática, 1999.

RANGEL, E. Livro didático de Língua Portuguesa: o retorno do recalcado. In: DIONÍSIO, A. P.; BEZERRA, M. A. O livro didático de português. 3. ed. Rio de Janeiro: Lucerna, 2005.

SILVA, E. T. Elementos de Pedagogia da Leitura. São Paulo: Martins Fontes, 1986.

TERZI, S. B. A construção da leitura. Campinas: Pontes; Editora da UNICAMP, 1995. 